\title{
Metformin as firstline treatment for type 2 diabetes: are we sure?
}

In this Analysis article (BMJ 2016;352:h6748, doi:10.1136/bmj. h6748) the first author, Rémy Boussageon, should have listed a second affiliation to Collège National des Généralistes

Enseignants, Montreuil sous Bois, France. In addition, in the contributors and sources section we should have given his initials as RB not RM.

Cite this as: BMJ 2016;352:1197

๑ BMJ Publishing Group Ltd 2016 